\title{
DESAFÍOS EN LA FORMACIÓN DEL CIRUJANO
}

\author{
Challenges in the training of the surgeon
}

El proceso de entrenamiento del cirujano enfrenta diversos desafios que es necesario comunicar a nuestra comunidad quirúrgica. Algunos de ellos atañen directamente al fenómeno curricular, sin embargo, hay otros aspectos que van más allá del ámbito de resolución de los centros formadores, pero inciden en la eficiencia del proceso.

Hasta hace 3 décadas el patrón predominante y único de enseñanza de la Cirugía estaba basado en el método Halstediano, a través del cual el candidato, poseedor de una sólida base científica, es sometido a repetitivas e intensas experiencias quirúrgicas supervisadas por un tutor, hasta demostrar autonomía en su ejecución.

Este método se ha venido modificando en forma progresiva a partir de la incorporación de la cirugía laparoscópica. Este cambio de paradigma educacional deriva de la posibilidad de reproducir el escenario quirúrgico en un recinto distinto al quirófano, el que está constituido por un laboratorio de simulación. Lo que inicialmente fue un dispositivo artesanal en el cual se podía reproducir la inserción de trocares y trabajar mirando un espejo, posteriormente se fue enriqueciendo con torres de laparoscopia y todos los elementos requeridos para efectuar prácticas laparoscópicas básicas y avanzadas. Esta instancia tiene además un componente ético no menor que consiste en evitarle al paciente el contacto con un cirujano que no ha tenido un entrenamiento previo.

Por este motivo es preciso destacar la necesidad que los cirujanos en formación tengan acceso a centros de entrenamiento de cirugía laparoscópica, teniendo en consideración que estos son sólo parte de la docencia recibida, ya que la especialidad requiere la presencia del docente tradicional que familiarice al residente en la palpación directa de la textura de los tejidos normales y alterados. Esto sin mencionar el insustituible aporte que efectúa la docencia tradicional en los aspectos actitudinales y valóricos de las competencias quirúrgicas.

La cirugía laparoscópica, sin embargo, además de representar un avance extraordinario tiene otros aspectos relacionados con la docencia que merecen análisis.

Uno de ellos se refiere a la curva de aprendizaje, que es más breve que la cirugía abierta, logrando conseguirse autonomía en un plazo menor al tradicional. Como consecuencia de ello, se ha observado una tendencia a la disminución del ascendiente tradicional de los docentes de larga experiencia.

Un riesgo asociado es la falta de exposición a cirugias laparotómicas. Está bien establecida la disminución de cirugías abiertas que ha ocurrido en las últimas décadas en una serie de patologías, destacando la reparación de aneurismas, la cirugía de la hemorragia digestiva y las laparotomías de origen traumático, entre otras, y su reemplazo por terapias menos agresivas e igualmente seguras para el paciente como la cirugía endovascular y procedimientos endoscópicos y embolizaciones para la detención de fenómenos hemorrágicos.

En el caso de la cirugía de la vesícula biliar, el riesgo derivado de la menor experiencia con cirugía abierta es más notorio. Esto debido a la complejidad de los pacientes que se deben convertir a cirugía abierta debido a procesos inflamatorios que hacen riesgosa la continuación con la técnica laparoscópica. Por esta razón hay una tendencia a dilatar el momento de conversión y, lo que es más grave, existe el riesgo que se ignore que se debe convertir.

Otra situación compleja está representada por las actuales necesidades asistenciales de los hospitales, con la cada vez mayor exigencia de optimizar la productividad, lo que asociado a médicos de staff sobrecargados de labores administrativas y llenado de formularios, dificulta el proceso docente debido a que éste implica una prolongación del tiempo de atención de los pacientes, al igual que del tiempo operatorio. 
Existe por otro lado la necesidad de optimizar el proceso docente intrapabellón, ya sea el residente actuando como ayudante y más aún cuando ejerce las funciones de cirujano. Esta interacción, a pesar de su antigüedad, no está estudiada ni menos normada. Lo que se recomienda es tomarse el tiempo para que exista un encuentro previo a la cirugía en el cual docente y residente discutan el plan quirúrgico y se anticipen cambios de estrategia frente a hallazgos no planificados.

Una vez finalizada la operación, en un encuentro similar, se debe evaluar el desempeño del residente, reforzando o corrigiendo maniobras efectuadas. Esto cobra mayor relevancia a la luz de comunicaciones que revelan que los intereses inmediatos a la cirugía difieren radicalmente entre tutores y residentes.

Mientras que para los docentes al enfrentar una cirugía, sus principales preocupaciones son la anatomía quirúrgica, la historia natural de la enfermedad y las condiciones esperadas al alta del paciente; a los residentes les interesa prioritariamente la selección del instrumental y material de sutura, así como el campo operatorio y la buena posición del paciente.

Los puntos tocados en estas líneas también deben ser compartidos con los residentes, quienes por iniciativa del directorio en el Congreso de 2013 constituyeron la seccional bajo los lineamientos de la Sociedad. Actualmente congrega a 150 colegas, los cuales una vez terminado su periodo de formación, pasarán a ser miembros afiliados.

En conversaciones con los directivos de los residentes se revela la necesidad de uniformar las posibilidades quirúrgicas de los diferentes centros formadores. La actual diversidad de instituciones representa el riesgo que cirujanos formados en determinados centros se vean expuestos a un número menor de oportunidades de entrenamiento.

Otra preocupación que los residentes han hecho llegar al Directorio es la revisión de criterios en cuanto a la pertinencia de rotaciones complementarias a la cirugía general como cirugía pediátrica, urología, ginecología y traumatología.

A lo anterior se debe agregar la carencia de metodologías objetivas de evaluación de habilidades y destrezas. La construcción de un instrumento de evaluación apropiado no es tarea fácil, sin embargo, es necesario aunar voluntades y experiencias de los distintos centros formadores para acometer esta tarea.

Cada vez más queda en evidencia el rol de la Sociedad de Cirujanos como institución que acoge estas inquietudes y que, dada la composición de sus integrantes provenientes de todas las Universidades, tiene la capacidad de diseñar las estrategias para su solución.

Dr. Marco Bustamante Z. Secretario General de la Sociedad de Cirujanos de Chile. 